\title{
Involving young people in the care and support of people living with HIV in Zambia: An evaluation of program sustainability
}

Eka Esu-Williams

Catherine Searle

Anderson Zulu

Follow this and additional works at: https://knowledgecommons.popcouncil.org/departments_sbsr-hiv

Part of the Demography, Population, and Ecology Commons, Family, Life Course, and Society Commons, Gender and Sexuality Commons, International Public Health Commons, and the Medicine and Health Commons How does access to this work benefit you? Let us know!

\section{Recommended Citation}

Esu-Williams, Eka, Catherine Searle, and Anderson Zulu. 2008. "Involving young people in the care and support of people living with HIV in Zambia: An evaluation of program sustainability," Horizons Research Summary. Washington, DC: Population Council. 


\section{Involving Young People in the Care and Support of PEOPLE LIVING WITH HIV in Zambia: An Evaluation of Program Sustainability}

I 2005, approximately 17 percent of the population of reproductive age in Zambia was infected with HIV and nearly 710,000 under the age of 18 were orphans, having lost a mother, a father, or both parents (UNICEF 2007). As the needs of people living with HIV (PLHIV) and orphans and vulnerable children (OVC) escalate, communities are seeking new ways of helping those infected and affected by the disease.

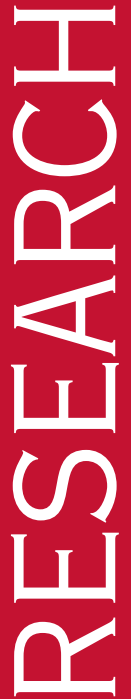
caregiving by its members, each club received kits that

To read more about this study, go to

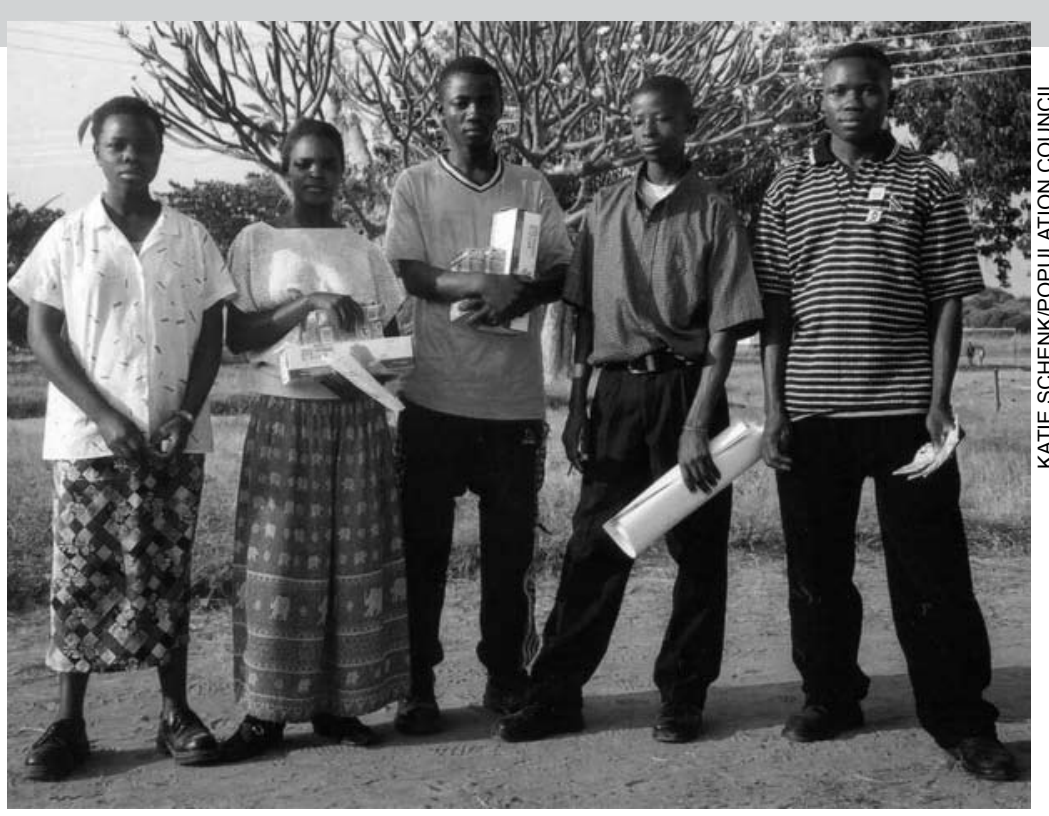

Trained youth caregivers in the Nchelenge district.

included gloves, disinfectant, cotton wool, and other caregiving supplies as well as two bicycles, and badges and aprons that identified the youth as part of a caregiving program.

Study findings indicated that trained youth caregivers were able to meet a range of needs of PLHIV and OVC to the satisfaction of their clients and that their efforts contributed to decreased isolation and stigmatization of AIDS-affected families. Youth provided a broad range of services for PLHIV including domestic work, basic nursing care, counseling on positive living, and referrals. Youth also assisted OVC by engaging them in recreational activities, communicating with schools about their needs, and making referrals to NGOs if additional support was needed.

www.popcouncil.org/horizons/projects/Zambia_YouthCareandSupport.htm
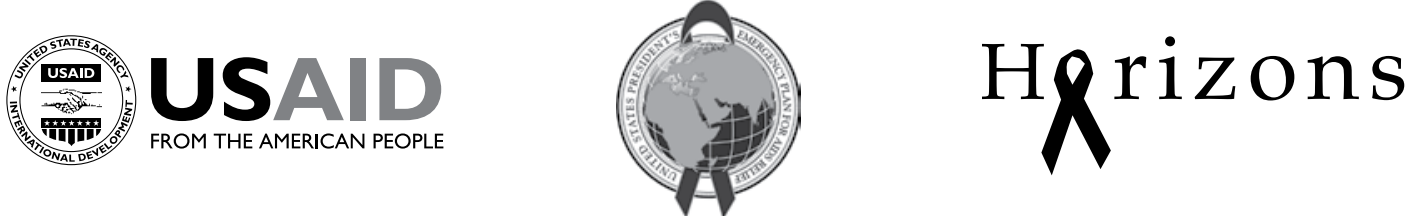


\section{Context of the Current Study}

The focus of the follow-up phase (20032005) was to strengthen local capacity to manage and sustain care and support activities by young people in the face of decreased inputs from Horizons. To prepare for a loss in funding, Horizons held extensive discussions with anti-AIDS clubs, community groups, and other stakeholders to identify how to program remaining funds (a 50 percent decrease from initial levels) in ways that would foster community ownership and sustainability. As a result, the funds were channeled through the Luapula Foundation, a local organization that was involved with the initial intervention and whose activities include advocacy, home-based care, and support for widows and orphans; the funds were used for capacity building and partnership development. In addition, two district-level management committees were formed to assume responsibility for running the project.

At the end of the follow-up phase, Horizons researchers examined the extent to which the anti-AIDS clubs continued caregiving activities, sustained and expanded partnerships with local organizations, and mobilized human and material resources to support the program.

\section{Methods}

In September 2005, 256 male and 218 female members of 32 school and community anti-AIDS clubs, aged 13-25 years, completed questionnaires. ${ }^{1}$ The mean age for males was 18.4 years and for females it was 17.2 years. Approximately three-quarters of respondents were currently in school, and more than 90 percent were single. A total of 73 in-depth interviews (IDIs) were also conducted. Eighteen were with adult club leaders, 18 with youth club leaders, 15 with youth caregivers, and 22 with PLHIV or their family members. In addition, four focus group discussions (FGDs) were conducted with PLHIV beneficiaries and their family members.

Quantitative data results are considered statistically significant at or below the 0.05 level; p-values were calculated using Pearson's chi-square test of independence. As findings emerged, participatory dissemination workshops with anti-AIDS club members and stakeholders were conducted to shed light on the results.

${ }^{1} 30$ of the 32 clubs participated in the initial intervention.

\section{Key Findings}

\section{The anti-AIDS clubs continued to}

function. Interviews with youth leaders showed that club membership ranged from 10 to 52 members (average $=26$ ) with equal proportions of males and females. Approximately two-thirds of club members were active. They noted that youth were attracted to join as a result of an invitation from existing club members and club leaders, and attending club activities. Additionally, youth were attracted to becoming part of what was perceived to be an important community service.

When club members were asked what they liked most about being in the anti-AIDS clubs, the most common response was learning about HIV. More than one-fourth of males and one-third of females said helping PLHIV (see Figure 1).

\section{Community members and the families of PLHIV} provided support to youth caregivers. Overall, results indicated that youth caregivers could count on help from the beneficiaries' families and from community members in caring for PLHIV and OVC. About two-thirds of club members surveyed reported that they received support from community leaders. According to a club member who participated in an IDI, "Chiefs give words of encouragement for us to continue the work we do, they also inform the community of our activities." More than two-thirds of youth surveyed noted that family and community members were involved in the youth caregiver program. Most commonly, they provided emotional support to PLHIV. They also assisted with care activities

Figure 1 "What do you like most about being a club member?"

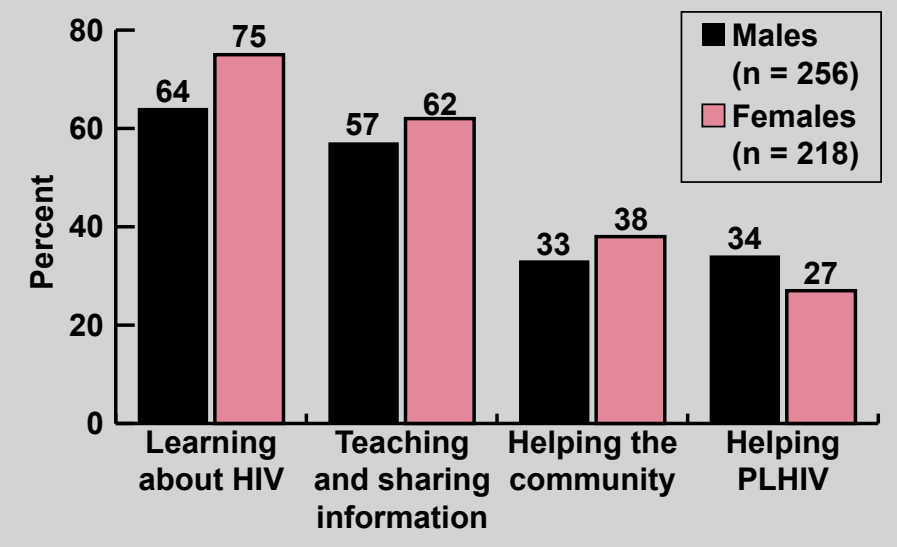


and identified clients for the program. One club member stated, "Families help us in care and support activities. In the past they just watched us, but this has changed." A club leader commented, "Recognition [of the program] is seen through the active involvement of the community in HIV/AIDS activities, and the positive support the community gives to youth caregivers."

\section{Anti-AIDS clubs expanded their partnerships} with organizations and services. IDIs with club leaders revealed that clubs were able to sustain existing partnerships and establish new ones during the followup phase of the project in order to continue program activities. These collaborations were with international organizations, government agencies and institutions, local non-governmental and community-based organizations (NGOs and CBOs), and local projects and services (see Table 1). When asked who their program most often partnered with, youth survey respondents mentioned health centers and schools, followed by NGOs/CBOs, home-based care teams, and the Catholic Diocese.

\section{The expanded partnerships resulted in the provi- sion of materials and resources for care activities, and training opportunities for club members. Clubs received a range of materials and services from partner organizations. Survey results indicated that some materials were more easily received than others. More than two- thirds of respondents reported receipt of HIV information materials and 40 percent obtained materials for medical care of PLHIV, including gloves and bandages. Less com- monly received resources were school fees for OVC, medi- cation, food, clothes, and other material goods.}

New partnerships allowed for new training opportunities. More than half of youth survey respondents reported having received some training from Horizons in the past year. But, more than one-third reported having received training from other sources, including from international NGOs (e.g., Africare, World Vision, Red Cross), local NGOs (ZNAN, NZP+, Youth Alive), faith-based organizations and churches, and the government.

Despite an increase in the number of organizations who provided training, fewer club members received training on key topics. Table 2 compares results from the 2002 endline survey of club members after the initial intervention period with results from the 2005 survey. While similar percentages received training on safety measures during caregiving, in 2005 club members were less likely to have received training in several areas. But they were more likely to have received training in AIDS treatment.

\section{The average number of people cared for by club} members increased over time. Despite a reduction in funding, the mean number of PLHIV and OVC cared for on a monthly basis was higher in 2005 compared to 2002. In 2005, males reported caring for an average of 5.5 PLHIV and 7.0 OVC per month (as compared to 4.0 PLHIV and 5.0 OVC in 2002). Females reported caring for an average of 5.7 PLHIV and 7.5 OVC (as compared to 4.0 PLHIV and 4.0 OVC in 2002).

Income-generating activities and proposal writing were the main ways clubs tried to raise money. As funding and material support from Horizons decreased, anti-AIDS clubs were able to secure resources in various ways. Some received donations of materials for caregiv-

Table 1 Partner organizations*

\begin{tabular}{|c|c|c|c|}
\hline International organizations & Government agencies & Local NGOs and CBOs & Projects/Services \\
\hline Food and Agricultural & \multirow{5}{*}{$\begin{array}{l}\text { Ministry of Health } \\
\text { Ministry of Education } \\
\text { Social Welfare } \\
\text { Ministry of Agriculture } \\
\text { District AIDS Task Force } \\
\text { Hospitals, clinics, and } \\
\text { rural health centers }\end{array}$} & SWAAZ & Neighborhood \\
\hline Organization & & NZP+ & Health Project \\
\hline Red Cross & & ZNAN & TB Team \\
\hline World Vision & & Youth Alive & Voluntary counseling \\
\hline Project Concern International & & ZOWA & and testing centers \\
\hline Rotary Club & & & \\
\hline
\end{tabular}

${ }^{*}$ Organizations in red indicate new partnerships (those formed after the initial intervention period).

Source: IDIs with club leaders 
Table 2 Type of training received in 2002 versus 2005

\begin{tabular}{lcc}
\hline & $\begin{array}{c}2002 \\
\mathbf{n}=\mathbf{4 9 6} \\
\%\end{array}$ & $\begin{array}{c}\mathbf{2 0 0 5} \\
\mathbf{n}=\mathbf{4 7 4} \\
\%\end{array}$ \\
\hline $\begin{array}{l}\text { Using safety measures for protection } \\
\text { during caregiving }\end{array}$ & 77 & 76 \\
HIV prevention for family members & 78 & 59 \\
Advising PLHIV on nutrition and hygiene & 72 & 40 \\
Referring PLHIV for counseling & 65 & 33 \\
Counseling PLHIV and their families & 58 & 33 \\
AIDS treatment & 0 & 10 \\
\hline
\end{tabular}

ing from hospitals and clinics, although it was noted that this was not in sufficient quantities. Club members also received training and mentoring from other institutions. This training was often informal, with individuals providing mentorship and hands-on training to club members.

The main activities used by clubs to mobilize resources were income-generating activities (IGAs) and proposal writing. Ten clubs wrote proposals for funding, of which three were funded at the time of data collection. Additionally, Horizons provided $\$ 100$ seed grants for IGAs to each club. Horizons and the Luapula Foundation engaged the Peace Corps to train clubs in farming methods including producing compost, bee-keeping, and raising animals.

Leaders of 17 clubs out of the 24 interviewed had started IGAs. The money and food generated from IGAs were used for various purposes, including assisting PLHIV with food and medications, buying materials for OVC, providing transport money for PLHIV and club members, and repairing bicycles. Approximately 40 percent of these activities were viable after six months. According to one club leader, "We have a piggery. We started with three pigs. We also have a cassava farm to assist clients with food. The money raised will be used to assist clients in a small way with their daily needs like soap and cooking oil...."

\section{PLHIV and caregivers remained positive about the}

program. In IDIs and FGDs, many PLHIV said that their lives had been positively influenced by the program.
It improved their outlook on life and lessened their sense of isolation from the community. Additionally, PLHIV learned valuable lessons from caregivers. One PLHIV said, "I have learnt how to care for myself, and I will not infect others. I always use a condom with my wife."

Despite programmatic challenges, including a lack of resources, PLHIV were largely satisfied with the program, stating that the caregivers were doing their best with available resources and were taking personal interest in their clients. While not blaming caregivers for continued gaps in care, PLHIV pointed out that food security, access to ARVs, and transportation to health care facilities are priorities that need to be addressed by future programs.

\section{Conclusions}

This study demonstrated the ability of anti-AIDS clubs to mobilize resources to sustain their programs and their dedication to caregiving activities even in the face of limited resources. Although support from Horizons decreased, clubs were able to sustain and expand partnerships with other organizations. Challenges that will need to be addressed include gaps in the availability of supplies, medication, and transportation for PLHIV and OVC. $\$$

\section{References}

Esu-Williams, Eka. et al. 2004. "Involving young people in the care and support of people living with HIV and AIDS in Zambia: Final report of an operations research study in Luapula and Northern Provinces," Horizons Final Report. Washington, DC: Population Council.

UNICEF. 2007. "The state of the world's children 2008: Child survival." New York: UNICEF.

Acknowledgments

Thanks to everyone who gave their time to participate.

Principal investigators included: Eka Esu-Williams, Catherine Searle, and Anderson Zulu of Horizons/Population Council.

Suggested citation: Esu-Williams, Eka, Catherine Searle, and Anderson Zulu. 2008. "Involving young people in the care and support of people living with HIV in Zambia: An evaluation of program sustainability," Horizons Research Summary. Washington, DC: Population Council.

\section{Hprizons}

pulation Council/

Horizons Communications Unit

4301 Connecticut Avenue, NW

Suite 280

Washington, DC 20008

\section{(P) Population Council}

Tel: $202-237-9400$

Fax: 202-237-8410

horizons@popcouncil.org

www.popcouncil.org/horizons
This research summary is made possible by the generous support of the American people through the United States Agency for International Development (USAID) and the President's Emergency Plan for AIDS Relief under the terms of HRN-A-00-97-00012-00. The contents are the responsibility of the Horizons Program and do not necessarily reflect the views of USAID or the United States Government.

๑ 2008 The Population Council Inc. 